\title{
[TRANS] EXISTÊNCIA: CORPOS ERRÁTICOS, GESTICULAÇÕES POLÍTICAS DE RESISTÊNCIA
}

\author{
[TRANS] EXISTENCIA: CUERPOS ERRÁTICOS, \\ GESTICULACIONES POLÍTICAS DE RESISTENCIA \\ [TRANS]EXISTENCE: ERRATIC BODIES, \\ POLITICAL GESTURES OF RESISTANCE
}

\section{Flavia Ferreira Silva ${ }^{1}$ e Mônica Botelho Alvim ${ }^{1}$}

${ }^{1}$ Universidade Federal do Rio de Janeiro, Rio de Janeiro/RJ, Brasil

RESUMO: Neste artigo trazemos a noção de errância proposta no campo da arte e da arquitetura, para fazer uma analogia do transitar no espaço urbano com o trânsito de gênero. Considerando que a errância embute uma concepção de circular pelo espaço da cidade apenas orientado pela experiência de afetação no espaço-tempo presente, discutimos a possibilidade de transitar entre masculinidades/feminilidades como um percurso corporal. Tomamos a noção de abjeção aqui para pensarmos a maneira desumanizada como essa errância é marcada, perdendo assim sua condição de alteridade. Consideramos que há um potencial transformador do trânsito corporal e, nesse sentido, o artigo propõe discutir alguns trabalhos artísticos que têm como emblema a quebra com a norma binária. Conclui que corpos errantes fazem com suas errâncias uma ruptura criativa com o instituído. Para além do gênero ancorado em padrões de azul ou rosa, uma infinita palheta de cores se abre para [trans]existências.

PALAVRAS-CHAVE: Errância; Trânsito; Abjeção; Arte.

RESUMEN: En este artículo traemos la noción de errancia propuesta en el campo del arte y de la arquitectura, para hacer una analogía del transitar en el espacio urbano con el tránsito de género. Considerando que la errancia incrusta una concepción de circular por el espacio de la ciudad orientado solamente por la experiencia de afectación en el espacio-tiempo presente, discutimos la posibilidad de transitar entre masculinidades/feminidades como un recorrido corporal. Tomamos la noción de abyección aquí para pensar la manera deshumanizada en que esta errancia está marcada, perdiendo así su condición de alteridad. Consideramos que hay un potencial transformador del tránsito corporal y en ese sentido el artículo propone discutir algunos trabajos artísticos que tienen como emblema la ruptura con la norma binaria. Se concluye que los cuerpos errantes hacen con sus errancias una ruptura creativa con lo instituido. Más allá del género anclado en estándares de azul o rosa, una infinita paleta de colores se abre para [trans] existencias.

PALABRAS CLAVE: Errancia; Tránsito; Abyección; Arte.

ABSTRACT: In this article we bring the notion of wandering proposed in the field of art and architecture, to make an analogy of the transit in the urban space with the transit of gender. Considering that wandering embodies a conception of circulating through an urban space only guided by the experience of affectation in the present spacetime, we discuss the possibility of passing between masculinities/femininities as a bodily course. We take the notion of abjection here to think of the dehumanized way this wandering is marked, thus losing its condition of alterity. We consider that there is a transformative potential of the corporal transit and in this sense the article proposes a discussion on some artistic works that have as their emblem the break with the binary norm. It concludes that errant bodies make their wanderings a creative break with the instituted. In addition to the gender anchored in blue or pink patterns, an infinite palette of colors opens to [trans] existences.

KEYWORDS: Wandering; Transit; Abjection; Art. 


\section{Introdução}

Transitar, explorar um espaço, ultrapassar fronteiras, percorrer um ambiente, o signo "trânsito" nos remete a todas essas possibilidades. Neste artigo pretendemos caminhar por noções que nos ajudem a pensar gênero como categoria fluida, algo que pode ser percorrido, rompendo com uma ligação direta entre sexo biológico e gênero. Pretendemos aqui discutir possibilidades flexíveis entre masculinidades e feminilidades como expressões da sexualidade que ultrapassam fronteiras rígidas impostas por sistemas normativos, considerando a ideia equivocada e difundida socialmente de que gênero seria uma categoria polar diretamente ligada à questão biológica do sexo.

Nessas múltiplas formas de viver e atuar, podemos perceber uma forma de trânsito, que aqui propomos compreender como uma forma de errância corporal. Paola B. Jacques (2012) define errância como uma experiência ligada ao percurso, à experiência de cruzar, viajar, percorrer um espaço, uma forma de apropriação do espaço urbano na ação de o experimentar, estar nele, o percorrendo de maneira presentificada, percorrer o espaço urbano não somente para se locomover de um ponto ao outro, mas estar na cidade de maneira a produzir afetações mútuas. A autora também destaca a experiência de errância como força de resistência em relação a uma certa analgesia que os atores urbanos estariam vivenciando na contemporaneidade, o que chama de "expropriação da experiência" (p. 19).

Fazemos aqui uma analogia entre errância, tal como proposto pela autora, e as identidades de gênero como experiência de trânsito, como possibilidade de percorrer o espaço do corpo no sentido de apropriar-se da experiência de transformação corporal como outras possibilidades de expressão da identidade de gênero. Assim, errância é utilizada aqui no sentido de reconhecimento de um território, de busca, de possibilidade de mudanças, apontando novas rotas.

É importante ressaltar que iremos nos ater neste trabalho ao trânsito de gênero em si, ao transitar, ao movimento de errância corporal como ato de resistência frente a forças disciplinadoras. Entendemos que há também aquelas/es que veem no trânsito orientado por uma categoria binária um lugar de encontro de si, que seus trânsitos são temporários, são trânsitos com porto de chegada, são pessoas que transitam para um gênero específico e que chegando nele se afirmam em um código de gênero mais ou menos normativo do que é ser um homem ou uma mulher. Em alguns desses casos, o prefixo trans é, inclusive, abandonado, uma vez que seus trânsitos tenham acabado. Ressaltamos que não pretendemos diferenciar aqueles que fazem um trânsito de gênero norteado por uma regra que tende ao binário daqueles que não almejam uma classificação clara; não se pretende aqui fazer qualquer julgamento de valor se há ou não um transitar mais ou menos válido: o que nos interessa investigar e discutir é o processo de transitar.

O tema se mostra relevante, uma vez que a expectativa de vida média de pessoas trans é de trinta e cinco anos, o que nos diz o quanto a visibilidade dessas pessoas desperta um movimento de aniquilamento, apagamento total do direito de existência trans, remetendo-nos à emergência que há em torno do tema, no sentido de legitimação e abertura de espaços, não só para a visibilidade, mas para a liberdade e possibilidade de expressão de subjetividades de pessoas trans. Nesse sentido, torna-se imprescindível buscar nas mais diferentes esferas - social, política, acadêmica etc. - pensar os dispositivos de enquadre corporal assim como os mecanismos que são utilizados como recurso, por parte daqueles que cometem crimes bárbaros contra a população trans, para se manterem impunes. 
O quanto a medicalização e a judicialização do direito ao corpo endossam práticas que destituem de humanidade aqueles que não se enquadram em padrões estereotipados, lançando seus corpos num lugar de abjeção. Tanto valorizando o que se acredita ser um padrão de normalidade quanto estigmatizando, como corpos abjetos que se constituem em um risco à sociedade, todas as corporeidades que não se enquadram naquele padrão. Temos como argumento central pensar as modificações corporais e até mesmo a maneira de experienciar a corporeidade de pessoas trans como uma errância, assim como aponta Paola Jacques (2012), uma experiência de percurso corporal que marque uma apropriação do espaço de si, do corpo vivido.

Considerando a arte como um campo privilegiado de produção de forças instituintes que transgridam o instituído, faremos essa discussão a partir de trabalhos de arte que dão visibilidade à existência trans, permanecendo na ambiguidade das experiências errantes de trânsito de gênero.

\section{Errância, errantes, erráticos, nômades: corpo dissidente}

A urbanista e mestre em filosofia da arte, Paola Jacques (2012), em sua obra Elogio aos errantes, parte da crítica de Charles Baudelaire feita em relação à modernização do espaço urbano, apontando para uma espécie de higienização desses espaços. Tal modernização teria como ponto principal a melhor fluidez dos automóveis e consequentemente das mercadorias que são comercializadas nos espaços urbanos, assim como a livre entrada e retirada de produtos das cidades. Baudelaire denuncia o fato de que as cidades são reprojetadas para o capitalismo, para o trânsito livre de mercadorias, e não mais para o transitar de pedestres, muito menos para aqueles que têm nas ruas seu lugar de morada, pelos bancos das praças, pelas ruelas, fazendo de marquises, passarelas e viadutos, abrigo. "Os personagens de Baudelaire, as prostitutas, os trapeiros, os mendigos, os escroques, vão sendo "varridos' das ruas, passam a ser figuras em extinção, como suas antigas ruas e casas” (Jacques, 2012, p. 46). A autora não deixa de destacar uma certa ambiguidade em Baudelaire, uma vez que é exatamente a partir da modernização que surge a figura do "flâneur",uma figura que ao mesmo tempo em que se encanta com a modernização, vai contra a primazia do deslocamento rápido que parece estar em voga com a abertura das avenidas e a reorganização dos espaços urbanos visando à melhor circulação. O que parece surgir é uma nova cidade, uma nova maneira de estar neste espaço e até um novo tempo, em que tudo parece estar mais acelerado, criando uma nova relação de espaço-tempo no ambiente urbano, modificando a experiência sensível dos sujeitos que o habitam.

O flâneur de Baudelaire se aproxima do errante que Jacques (2012) nos apresenta, uma vez que, como a própria autora afirma, sua obra, ao fazer um elogio aos errantes, "pretende ser um elogio da valorização de um tipo de experiência cada vez mais rara nas cidades contemporâneas: a experiência urbana da alteridade" (p. 11), ou seja, a experiência de estar na cidade de maneira corporificada, afetando o espaço urbano e sendo afetado por ele, sem um ponto de chegada como objetivo, mas buscando a própria vivência de se deixar afetar pelos espaços. Jacques (2012) se remete aos errantes urbanos como sendo aqueles que trazem vida à cidade. Podemos sentir a presença desse outro que cria movimento no cenário frio de concreto e asfalto, deixando rastros de existência da vida gravados em grafite nos muros, marcados nas vias com as presenças de barracos sob viadutos, 
entre outras manifestações de presença. Tudo aquilo que se produz em nossos corpos quando nos deparamos com a frieza do concreto - as marcas de tiros nos muros de determinados lugares, o grafite artístico multicolorido, a pichação de indignação política - nos afeta e convida a nos deslocar dos lugares e modos de estar naturalizados.

Michel de Certeau (2002) discute o espaço da cidade e descreve dois planos, que denominamos aqui um plano alto e um plano baixo. Elevados ao plano alto, assumimos a posição de uma figura mítica que pode voar, como Ícaro, ou de um "deus voyeur" (p. 171), com um olho divino ou solar e adquirindo uma visão à distância do todo da cidade. Tal visão, que pode ser experimentada mais concretamente do alto de um arranha-céu, congela a cidade e esconde o movimento e o burburinho, nos distanciando da experiência. Ao descermos ao plano baixo, encontramos os praticantes ordinários da cidade com seus corpos que transitam e escrevem um "texto urbano" (p. 171) que eles mesmos não podem ler. Esse espaço da cidade é o palco de uma "estranheza do cotidiano que não vem à superfície, ou cuja superfície é somente um limite avançado, um limite que se destaca sobre o visível" (p. 172). O filósofo propõe investigar práticas que fogem do espaço geométrico onde se dão as construções panópticas, para buscar outra espacialidade traçada na mobilidade opaca, "uma cidade transumante, ou metafórica" que se insinua "no texto claro da cidade planejada e visível” (p. 172).

Assim, Certeau busca os movimentos contraditórios, astúcias e poderes sem identidade que não se podem gerir, a despeito das regulações e jogos disciplinares, o que o aproxima das discussões que fazemos aqui em torno da errância. Ao propor o ato de caminhar como um espaço de enunciação pedestre, ele põe em questão a capacidade do sistema organizador da cidade de submeter completamente as pessoas às suas regras normativas e acredita na possibilidade transgressora dos caminhantes, que mesmo submetidos aos traçados urbanos, são sujeitos de enunciação que criam uma retórica ambulatória a partir de gestos que conferem estilos distintos ao espaço. "Assim, as narrativas urbanas resultantes dessas experiências realizadas pelos errantes, sua forma de transmissão e compartilhamento, podem operar como potente desestabilizador de algumas das partilhas hegemônicas do sensível e, sobretudo, das atuais configurações anestesiadas dos desejos". Nessa direção, Jacques (2012) aponta a potência transgressora das narrativas urbanas.

A autora discorre a respeito de uma estratégia de apaziguar desejos em um movimento de homogeneização da experiência urbana contemporânea. Essa espécie de pacificação dos espaços públicos estaria a serviço de uma higienização de tais espaços, uma espécie de esterilização da experiência de se estar na cidade.

A pacificação do espaço público, através da fabricação de falsos consensos, busca esconder as tensões que são inerentes a esses espaços e, assim, procura esterilizar a própria esfera pública, o que, evidentemente, esterilizaria qualquer experiência e, em particular, a experiência da alteridade nas cidades. (Jacques, 2012, p. 14)

Estamos aqui abordando errância retratada por Jacques sob dois aspectos: como analogia em relação à construção corporal que vem dando à noção de gênero um plural de possibilidades; e no que se refere ao fato de que os corpos em trânsito, ao romperem com padrões naturalizados, sejam empurrados para fora dos espaços públicos por uma lógica de esterilização, como se fosse necessária sua retirada da cena hegemônica contemporânea. 
Tal como já anunciamos anteriormente neste artigo, trazemos aqui a experiência de trânsito, no que tange ao gênero, como possibilidade de apropriar-se de seu corpo a partir de uma construção errática de si, no sentido estético da errância, qual seja uma apropriação do próprio corpo na afetação que surge com o transitar através de diferentes traços que marcam gênero. Traçamos um paralelo entre a experiência trazida por Jacques (2012) - na qual o transitar no espaço urbano de maneira presentificada cria novas possibilidades de se estar na cidade - e o transitar de gênero de pessoas trans. Esse paralelo refere-se à criação de novas possibilidades de ser e estar no mundo, para além do corpo que é enquadrado por um sistema de normas. Um corpo que é singular, dissidente do hegemônico, que transcende o corpo biológico normatizado para assumir-se como [trans] existência.

Careri (2013) contrapõe as características do espaço sedentário e do espaço nômade: o primeiro seria mais denso, sólido e cheio em relação ao segundo. Ele compara o espaço nômade a um deserto ou ao mar, lugares onde, ao caminhar, deixamos apenas um "rastro móvel e evanescente" (p. 42). O movimento de percorrer traça o espaço do percurso como o único sinal estável dentro do vazio, e o espaço do ir é onde "se celebra o rito da eterna errância" (Careri). O autor associa o espaço nômade ao espaço errático para estabelecer, a partir da noção de percurso, uma relação entre arquitetura e nomadismo que transgride a concepção comum de que "a arquitetura teria nascido como necessidade de um espaço do estar em contraposição ao nomadismo, entendido como espaço do ir” (p. 40).

Poderíamos pensar essa oposição entre nomadismo e sedentarismo em relação ao corpo em trânsito de gênero para pensar no corpo como um espaço nômade, um espaço onde se celebra o rito da errância. Careri (2013) afirma que: "Na ausência de pontos de referência estáveis, o nômade desenvolveu a capacidade de construir o seu próprio mapa em cada instante, a sua geografia está em contínua mutação, deforma-se no tempo com base no deslocar-se do observador e no perpétuo transformar-se do território” (p. 42). Nossa referência aqui são pessoas trans, pessoas que transitam corporalmente em uma construção de gênero que foge ao determinismo homem/mulher, para serem mulheres com pênis, homens com vaginas, intersexo, entre tantos outros, desestabilizando pontos de referência que naturalizam a percepção. O que pretendemos com este artigo é discutir práticas de trânsito, de errância corporal que apontem para a possibilidade de uma vivência de si mais singular, próxima dos desejos individuais, que não sejam reféns de uma série de normativas apaziguadoras das diferenças.

Nesse sentido, abordamos no trabalho vivências que margeiam, que em suas existências são força de resistência e gesticulação política, uma vez que denunciam um sistema excludente e criam pontos de ruptura e possibilidades de [trans]existir.

Antes, porém, discutiremos a abjeção como forma de exclusão do espaço público dos corpos em trânsito errático.

\section{Errância e corpos abjetos}

Abjeção pode ser definida como um estado degradante de baixeza; assim, algo abjeto ultrapassa as barreiras do humano, desvirtua-se em algo ininteligível, desprezível, monstruoso. Butler (1990/2016) destaca os esforços feitos por uma determinada política, em que identidades são normatizadas em uma espécie de "unidade" ininteligível, ao que a filósofa questiona como sendo uma provável fonte de fragmentações; uma vez que fecha hermeticamente signos identitários, a sociedade exclui outras possibilidades de identidade. 
Considerando que a articulação de uma identidade nos termos culturais disponíveis instaura uma definição que exclui previamente o surgimento de novos conceitos de identidade nas ações politicamente engajadas e, por meio delas, a tática fundacionista não é capaz de tomar como objetivo normativo a transformação ou a expansão dos conceitos de identidade existentes. (Butler, 1990/2016, p. 41)

A abjeção é salientada por Ortega (2008) como um "pavor da carne”, uma rejeição corporal, que remete a morte, vísceras, fluidos, partes do corpo que devem ser expelidas, expulsas, para que este corpo, reduzido à dimensão de animalidade, possa se inscrever na ordem instituída culturalmente. Pessoas com gênero transitório/errante trazem em seus corpos a marca dessa dimensão carnal pavorosa, suas mudanças físicas, silicones, hormônios, e uma espécie de viagem errante em um universo corporificado de sangue, suor, saliva, tecidos cortados, reinventados, ressignificados, redesenhados anatomicamente e subjetivamente. São corpos que se reconstroem em uma nova perspectiva de ser, tendo como horizonte uma construção de identidade que escapa à norma binária, para uma imensidão de possíveis.

Butler (2016) discute o caráter identitário da questão de gênero e seu desdobramento sobre os corpos politicamente marginalizados, destacando que não há espaço para a transformação nas estratégias políticas de reger corpos. Porém, há aqueles para os quais a norma causa estranheza, que a norma em sua dimensão de engessamento não impede a busca por novas possibilidades, por transformação, transgressão, atualização do que está instituído, sedimentado. Nesse nó social, surge um grande campo de tensões, do outro lado há aqueles que entram no normativo de maneira naturalizada, à esses que os dissidentes do gênero binário causam estranheza, ininteligibilidade, desprezo e até impulso de aniquilamento.

Esse impulso decorre de um tipo de reação por parte da normatividade instituída que, movidos pelo pavor de uma determinada carne, como já colocado por Ortega (2008), percebem esses sujeitos-corpos como corpos-objetos carregados de sentido degradante e desprezível, que não seriam dignos de existência.

Hélio Silva (1993), em sua pesquisa com travestis na Lapa, Rio de Janeiro, afirma logo no início do seu livro, que busca afirmar a dimensão humana da travesti da Lapa, o que nos leva a pensar o caráter desumano que estaria implícito na figura travesti, esse corpo "desenquadrado" e por isso abjeto, é desprovido de humanidade, é monstrificado.

A característica de errante da pessoa trans, que de alguma maneira a coloca como estrangeira em meio à hegemonia da norma binária, causa estranhezas, redireciona as possibilidades de expressão performática e também os direcionamentos de orientação de desejo. Uma mulher trans pode, por exemplo, direcionar seu desejo a outras mulheres, como no pequeno documentário Amanda e Monick (Pinto, 2011). Amanda se autoidentifica travesti, trabalha como prostituta em Barra de São João, Paraíba, tem um relacionamento amoroso com Nilda, mulher cisgênero que está grávida de Amanda. As fronteiras são borradas nos discursos de Amanda e Nilda, Amanda expressa seu desejo de ser mãe, e gerar um filho de seu próprio corpo, porém sabe da impossibilidade biológica e percebe na gravidez de Nilda a possibilidade de exercer sua maternidade de maneira plena, em um lar marcado pela luta diária da sobrevivência e o amor entre as duas.

Aqueles e aquelas que transgridem as fronteiras de gênero ou de sexualidade, que as atravessam ou que, de algum modo, embaralham e confundem os sinais considerados "próprios" de cada um desses territórios são marcados como su- 
jeitos diferentes e desviantes. Tal como atravessadores ilegais de territórios, como migrantes clandestinos que escapam do lugar onde deveriam permanecer, esses sujeitos são tratados como infratores e devem sofrer penalidades. (Louro, 2013, p. 89)

Louro (2013) traz em seu texto considerações que corroboram nossa proposta de pensar essa condição de errância, de percurso pelas margens dos caminhos instituídos e de exclusão e não pertencimento desses corpos, desprezados, abjetos e merecedores de "sofrer penalidades”. O que sublinha a questão da violência que é direcionada a esses corpos; violência que parte de um controle em nome do normativo, e que é exercido por várias instâncias da sociedade.

Butler (2011) reflete a respeito da representação que é feita daquele que marca a diferença. A autora sinaliza que a "personificação às vezes opera sua própria desumanização" (p. 24) e o quanto essas representações e personificações surgem de movimentos midiáticos que de alguma forma instituem de maneira normativa aqueles que são adequados e os que não o são, que ficam de certo modo desprovidos de humanidade. A autora se refere à personificação como aquilo que é culturalmente aceito, e até estimulado pelas mídias que sejam performados por nós, nosso gestual no mundo social sendo guiado por esses códigos de conduta previamente desenhados midiaticamente. Seriam formas adequadas de ser com as quais nos identificamos e buscamos personificar em nós, como, por exemplo, ter um corpo magro é aceito em detrimento de corpos vistos como gordos, ou mesmo um corpo que é visto como sendo de um homem sendo desenhado nas curvas do que é considerado feminino. "O 'eu' que vê o rosto não se identifica com ele: o rosto representa algo com o que nenhuma identificação é possível, uma realização da desumanização e uma condição para a violência” (Butler, 2011 , p. 27). A filósofa marca o movimento de esvaziamento da humanidade advindo de processos de identificação ou não com determinada representação, e com isso a tentativa de apagamento das diferenças que por ventura não tenham sido superadas no encontro com esse outro.

O problema do outro é uma questão central na filosofia e na psicologia e está intimamente relacionado ao corpo, tendo sido abordado por Merleau-Ponty (1964/2012) ao longo de toda sua obra. O filósofo discute na obra A Prosa do Mundo a ideia do mundo compartilhado entre mim e o outro de tal forma que consigo identificar no gesto do outro sua própria existência, uma vez que fazem ambos parte do mesmo campo de existência, eu-outro-mundo estão sempre impactando e sofrendo o impacto dessa relação. O que nos leva a pensar a "torção" de mundo que se apresenta quando vejo no corpo físico (Körper) do outro o que a biologia aponta como uma mulher e esse outro "torce" em sua experiência vivida (Leib) e gesticula no mundo de acordo com o que eu acredito ser um gesto de homens. Essa torção faz com que eu tenha que lidar com o esvaziamento do sentido do que é ser homem/mulher no mundo, ou seja, no limite, posso me esvaziar de minha própria masculinidade/feminilidade, para dar espaço a uma outra possibilidade de gênero, de gesticulação de estar no mundo como homem ou mulher. Quando o outro cria essa possibilidade, ela passa a ser também um possível para mim e aquilo que está sedimentado em mim enquanto o que é gênero, e me parecia um "porto seguro" - como colocado em Bento (2014) -, assegurado de uma maneira que me parecia "natural" e vinda do biológico, é torcida. $\mathrm{O}$ que pode repercutir na minha singularidade de diversas maneiras possíveis. Pode ser para mim força de criação de outros modos de existir e de me relacionar com o outro diferente, mas também pode surgir como ameaça e, para colocar isso fora de meus espectros de possíveis, pode ser preciso negar esse possível no outro. 
O caráter transgressor e político da arte é elemento-chave para pensarmos essa "torção de mundo" como fenômeno de desnaturalização da percepção, o que nos obriga a um trabalho dado no plano baixo da experiência, em contato com a aspereza e opacidade do mundo e do outro, na vivência do estranhamento e do dissenso.

\title{
Coreografias urbanas e errância transcoreografada: arte e política
}

\author{
Dança Perdida \\ Na dança voluptuosa \\ Do passo da bailarina, \\ A dor do compasso de todas as rimas. \\ O segredo está na liberdade do movimento.
}

\section{ATENÇÃO}

Eu não acredito em liberdade, muito menos em movimento, muito menos em deus, nem mesmo em você, ou nele, ou nela.

Às vezes nem em mim mesmo.

Às vezes sou fomento.

Às vezes, esquecimento.

Às vezes volto a ser movimento.

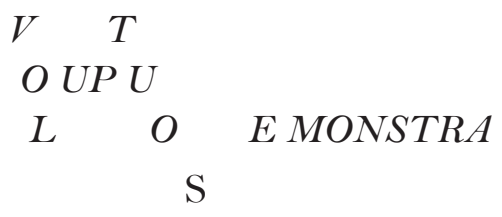

\section{Incrédula}

Eu não acredito em mim. (Autoria Coletiva, 2017, p. 17)

Na poesia "Dança Perdida", escrita de maneira coletiva por estudantes do curso Transformação, projeto voltado à preparação de pessoas trans para o Exame Nacional do Ensino Médio (ENEM), os autores parecem trazer, na metáfora da dança, a maneira com a qual não estão coreografados com o movimento hegemônico. O texto traz figuras como a dor, a liberdade, movimento, esquecimento, voluptuosidade e monstruosidade, questões que compõem o universo trans e são da ordem do que é vivido, experienciado por essas pessoas que têm na abjeção de seus corpos a "dança perdida" do dia a dia. A evasão escolar, a violência, discriminação, marginalização, são as muitas formas de se perder a dança social, a dança por uma existência vista, legítima. 
André Lepecki (2012), em seu ensaio Coreopolítica e coreopolícia, se refere à coreografia como "prática política e como enquadramento teórico que mapeia, de modo incisivo, performances de mobilidade e mobilização em cenários urbanos de contestação" (p. 42). O autor traz a prática artística como ponto de tensionamento social que pode chegar a criar "fissuras do urbano", assim como em Jacques (2012) o movimento de errância é concebido. Lepecki (2012) nos fala da face política que há na arte, seu caráter sensível, visível e invisível, que acaba por revelar formas [ou fôrmas?] de "coreopoliciamentos sutis que (pre)definem o espaço urbano como imagem do consenso neoliberal” (p. 42). O autor recorre a Jacques Rancière e Giorgio Agamben para traçar a relação entre arte e política, que estariam para esses autores entendidas de maneira coconstitutivas. Afirma que para Rancière a arte está para além de um "regime estético", estaria no campo do sensível de maneira a ativar novas possibilidades de enunciação e percepção, criando novas potências de subjetivação.

Lepecki (2012) vale-se do que Rancière chamou de dissenso, como aquilo que une arte e política em um movimento, uma dinâmica que produz frestas nos códigos comportamentais de uma determinada sociedade. Já em Agamben, arte e política seriam atividades humanas que se ocupam na "abertura de potências": "A arte é inerentemente política, porque é uma atividade que torna inativos, e contempla, os hábitos sensoriais e os hábitos gestuais dos seres humanos, e, ao fazê-lo, os abre para um novo uso potencial” (Agamben, por Lepecki, 2012, p. 44). Podemos dizer assim que a arte acaba por descentrar os gestos enformados socialmente, e tem exatamente aí sua face política, no sentido de criar possibilidade de novas maneiras de gesticulação.

A dança entra no trabalho de Lepecki (2012) não como metáfora, mas como aquilo que irá "teorizar o contexto social [de] onde emerge", força de mobilização, "A dança operária também como uma epistemologia ativa da política em contexto" (Lepecki, 2011 , p. 46, grifos do autor). Cita Hewitt, "o que chamo de 'coreografia' não é simplesmente um modo de pensar a ordem social: é também uma via para se pensar a relação estético-política” (Hewitt, por Lepecki, 2012, p. 46). O ensaio de Lepecki traz à tona a maneira com a qual coreografias urbanas são lançadas e manipulam corpos diante da relação com o urbano e com o outro, ou seja, com a política. Na poesia "Dança Perdida", o coletivo transformação, se refere àqueles que não são convidados a dançar, que por não terem em seus corpos gesticulações do que é "predefinido" como coreografado, não possuem direito ao "baile".

Obviamente, todas essas imagens que a mídia global produz, reproduz e faz circular são já coreografadas pela câmera e por um aparato de representação midiático que, em si mesmo, já é produtor e reprodutor de certa imagem do que é fazer política e manifestar dissenso no espaço urbano. (Lepecki, 2012, p. 50)

Mais uma vez nos deparamos com a questão do aparato de representação midiática, as imagens midiáticas que produziriam uma certa ordem, que poderiam ser compreendidas do ponto de vista da análise de Lepecki (2012), como uma coreografia do espaço. A figura da polícia entra como a que delimita as possibilidades desse bailar, em um movimento ambíguo "entre a sua função de fazer cumprir a lei e a sua capacidade para a sua suspensão arbitrária; uma figura cujo espetáculo cinético é de chamar para si o monopólio sobre a determinação do que, no urbano, constitui um espaço de circulação" (Lepecki, 2012, p. 51). O autor traz em seu ensaio alguns exemplos de como de alguma maneira a presença da polícia faz com que o urbano ganhe uma coreografia clara dos espaços que podem ser utilizados, e da maneira com a qual se pode espacializar, dançar, nesses espaços. 
Trago também aqui um exemplo, que se distingue dos de Lepecki, mas que gira ao redor da mesma ambiguidade já sinalizada pelo autor: a artista trans Rosa Luz fez uma performance na rodoviária de Brasília, na qual, no horário de maior movimento, a atriz fica sem camisa no meio da escadaria do local, exibindo parte do seu corpo que foge à norma: um corpo biológico de homem, com seios femininos construídos, à mostra, gerando impacto nos transeuntes que manifestam expressões que variam entre ofensas constrangedoras e palavras de apoio.

O objetivo de Rosa era discutir gênero, transfobia, liberdades individuais e a fronteira que surge no que se refere a corpos nus e gênero. Rosa declara: "Foi um momento de troca. Eu me senti ótima no final, fui abraçar minhas amigas e é tudo nosso. Se o nosso corpo é uma falha no sistema, vamos usar nosso corpo para apontar essas falhas" (Rosa, por Lucon, 2016). Fica claro na fala da artista o caráter de subversão provocativa que ela pretendia com sua arte, criando descentramentos e produzindo discursos, reflexões etc.

Achei que poderia acabar na delegacia. Se me prendessem, estariam me reconhecendo como mulher (homens podem ficar sem camisa publicamente sem problemas). Mas como você me reconhece como mulher, se o Estado não me reconhece dessa forma? É uma contradição.(Rosa por Lucon, online, 2016)

Rosa denuncia também o paradoxo normativo; corria o risco de ser presa, mas caso isso ocorresse seria uma maneira da instituição polícia afirmar Rosa como mulher. Para a levarem presa teriam que partir do pressuposto que ela é, sim, uma mulher, e seu ato de estar sem camisa estaria agindo contra as normas legais que dizem respeito a seios femininos desnudos como um atentado ao pudor. Mas sendo Rosa legalmente homem, o que constava em seus documentos, sua participação no espaço do mundo a permite ficar sem camisa em espaços públicos. A polícia, nesse caso, se perde em sua própria coreografia e se vê rendida a permitir que Rosa se expresse de maneira artística com seu corpo feminino.

E assim pessoas trans vão especializando sua existência, buscando pontos de ruptura do sistema hegemônico, lugares em que suas gesticulações não tenham como ser negadas, criando novas coreografias. A maneira com a qual a sociedade percebe e dança a coreografia denunciada por Lepecki (2012) "demonstra como o policiamento enquanto coreografia do fluxo do cidadão é algo profundamente arraigado, entranhado e que forma e deforma o espaço do urbano" (p. 52). Nitidamente temos um espaço urbano destinado a um recorte de classe, a um recorte de gênero, a um recorte de existência. E é a errância desses corpos vistos como deformados, abjetos, indecorosos, que vai abrindo novas possibilidades de circulação e de resistência.

Tanto na coreopolítica de Lepecki (2012) quanto na errância de Jacques (2012) podemos perceber que há uma tentativa de exclusão através do recorte arquitetônico que o urbano apresenta. Marcando os lugares transitáveis e não transitáveis, espaços habitáveis ou não, a coreografia pré-desenhada marca o caminho que permite a passagem da maioria. Porém os dissidentes, aqueles que habitam os guetos, as margens, os lugares inabitáveis, transitam e conhecem um outro lado do urbano, as ruelas, as pedras colocadas embaixo dos viadutos, as marginais das rodovias, os bancos de praças divididos ao meio para que mendigos não durmam ali, entre tantos outros lugares. São esses lugares que vão sendo ocupados por aqueles que não transitam no meio, mas que são os que produzem movimentos de errância e vão redesenhando os caminhos urbanos e os caminhos possíveis da vida. 


\section{Transrevolução: “artivismo" dissidente e protagonismo}

É bonita a força de cada um desses trabalhos, o discurso, a representatividade, a união, a parceria. Quando existe espaço para que esses encontros aconteçam, tudo fica mais forte. Ser contemporânea das pessoas citadas e ter a experiência de outras que não estão aí, mas que fizeram muito com sua força política e musical, é engrandecedor. Quanto mais chegarmos a lugares que nunca chegamos, mais serão lugares importantes, porque socialmente somos excluídas de muitos desses postos de representação. Levar nossas vozes para palcos e embates políticos é um bem danado porque outras pessoas que não chegaram ali se sentem representadas no nosso discurso. Não podemos falar por todo mundo, mas quando fazemos por nós acho que nos aproximamos disso. (Liniker, conforme Colling, 2017, p. 33)

A frase da artista Liniker (Colling, 2017) faz parte do dossiê da Revista Cult edição 226, em que o tema abordado é o que Leandro Colling chama de "artivismo das dissidências sexuais e de gênero”. O dossiê trazido nesta edição da revista é composto por vários textos de diferentes profissionais e acadêmicos que buscam analisar o cenário contemporâneo em que a arte, e principalmente a arte queer ${ }^{1}$ surge com a emergência de se fazerem ouvir, ver, existir. Para Colling (2017), um dos principais motivos dessa emergência se dá diante do crescimento do conservadorismo fundamentalista, que tem nos temas da sexualidade e de gênero seu principal foco de crítica. O que a revista busca é retratar o quanto "arte e ativismo andam de mãos dadas na construção da politização da abjeção e de uma crítica ao enquadramento normativo dos gêneros e das sexualidades" (Sant'ana, 2017, p. 23). Nesse cenário a arte surge de maneira a afirmar narrativas, legitimar falas, fazendo visível tudo aquilo que a norma tenta invisibilizar, empurrando para a margem, ou até aniquilando.

Estamos trazendo aqui a ideia de performance artística como potência de abertura, de quebra de sentidos para retomada, atualização e transcendência, partindo das performances trans, nos vários campos da arte. Nessa perspectiva podemos pensar a performance de gêneros para além da dicotomia, gêneros que desenlaçam a expressão masculino/feminino, para a singularização e multiplicidade da experiência de gênero vivida para cada ser, abrindo possibilidades de masculinidades, feminilidades, travestilidades, fluidez de gêneros, trânsito. É essa experiência no mundo, esse encontro com as coisas, com o outro, com aquilo que me afeta, me interroga, e que é sempre provisório, já que está sempre passível de ser retomado e atualizado por novas experiências, que produz em mim ranhuras e me faz possível revolver o que já foi sedimentado em meu horizonte de passado, mantendo viva a historicidade da existência. É nesse descentramento que a performance artística funciona como campo de abertura, na sua força de provocação, que abre novos caminhos a serem transitados, novas coreografias, novas possibilidades de errância.

Durante o evento "Puta Dei", realizado pelo Instituto de Medicina Social (IMS), a estudante de História da Arte da Universidade do Estado do Rio de Janeiro (UERJ), Tertuliana Lustosa pronuncia a seguinte frase durante uma apresentação performática em que a travesti se despe de suas roupas e seus documentos: " $O$ orgulho de ser estranha". Tertuliana (2017) fica nua e gradativamente vai expondo documentos relativos à sua trajetória de transição. Entre eles estão: seu trabalho de cordel, a logo de uma lata de leite - não leite materno ou de vaca, mas leite de travesti - leite que é retirado de seus próprios seios, devido ao uso de hormônios femininos em seu processo de trânsito. Tertuliana também expõe sua certidão de nascimento, e nela sua regionalidade piauiense, seus cartões de 
consulta ao Hospital Pedro Ernesto, e chama atenção para o caráter patologizante desses documentos. Chegando a mostrar também um ofício que diz ser um direito da artista ser tratada pelo seu nome social, denunciando um paradoxo, pois no mesmo documento ela é tratada pelo nome civil.

Tertuliana está nua, seu nu parece constranger o público, porém é a ela que esses paradoxos e processos patologizantes constrangem, agridem, marginalizam. Sua denúncia é explícita, a academia desnuda a questão trans, porém o nu trans constrange. A pergunta que a travesti faz ao começar sua performance é: "O que a hegemonia pode fazer pela diferença?” Com essa pergunta, Tertuliana nos convoca a todos, que de diferentes maneiras, compomos e estamos inseridos em espaços-tempos hegemônicos.

A subversão dos corpos que é proposta pelas pessoas trans traz em si a marca emblemática do ato artístico, no sentido de proposição de uma nova estética, de convocar a experiência, movimentar a dimensão estética, gerando a possibilidade de instauração de novos significados. No caso em questão aqui, a retomada do que vemos como masculinidades, feminilidades, travestilidade, trânsito.

Na performance de Tertuliana (2017) na UERJ, seu nu real traça um fio intencional em direção a processos que a despem cotidianamente, de maneira simbólica. Para o filósofo Merleau-Ponty (1945/2011) o mundo não é algo que eu penso; antes disto, eu o experiencio de maneira pré-reflexiva, o mundo é aquilo que vivo, é campo de experiência. Alvim (2014) traz a ideia de que neste campo de experiência o sujeito é, ao mesmo tempo, aquele que faz e é feito pelo mundo, assumindo também o lugar de objeto cultural no mundo, e tendo "um status privilegiado - é sujeito e objeto, sentiente e sensível, vidente e visível. A obra de arte é expressão viva do entrelaçamento de homem e mundo e veículo de passagem do visível ao invisível. A ação criadora é a protagonista da visibilidade” (p. 68). Podemos assim dizer que é na subversão desses corpos - que vão se construindo, se apresentado de maneiras diversas, e que se fazem visíveis através da arte - que há um protagonismo da criação de si, a pessoa trans grita sua transição e se faz ver em sua ação criadora de novas corporalidades.

A respeito da performance de Tertuliana (2017), Russo e Carrara (2017), docentes do Instituto de Medicina Social (IMS), constroem a seguinte narrativa:

O gesto de Tertuliana não valeria de nada se só provocasse risos nervosos, rumores, rubores; se apenas motivasse o escândalo ou o loquaz silêncio do arquear desaprovador de sobrancelhas. Ele demanda muito mais de nós. Exige, sobretudo, uma profunda reflexão sobre nossas práticas de pesquisa, nossos conceitos e nossos preconceitos; e no âmbito do UERJ. Resiste, nossas formas de resistir. (Russo \& Carrara, online, 2017)

Fica clara a importância da ocupação dos espaços acadêmicos pela provocação, pelos descentramentos, para que a produção acadêmica possa interrogar-se, refletir sobre sua prática e buscar sentidos para a sua produção de saber, retomada e possibilidade de novas aberturas instituintes. Tanto em Alvim (2014) quanto em Russo e Carrara (2017) nos é apresentada a importância do contato com o saber da experiência vivida somado ao saber acadêmico para que não se reproduza a exclusão, produzindo ressonâncias, ressignificações que provoquem mudança, transformação. 
Outra performance artística que trazemos aqui fala do tema da violência e aniquilamento como mote. Na peça Gisberta ${ }^{2}$, o ator cisgênero Luis Lobianco encena o texto de Rafael Souza-Ribeiro (2017), trazendo uma narrativa em que o humor se mistura a gritos roucos e fortes, humilhações e recordações de carinho e amor, contando a história da travesti assassinada em um processo lento, cruel e doloroso, história que vai sendo tecida com carinho e respeito. O texto traz na lembrança de familiares, amigos e documentos da época o trânsito de Gisberta, a infância comum a tantos outros que não estão em conformidade com o que é esperado, coreografado socialmente. Ele mostra os questionamentos, a tentativa de patologização, a deslegitimação, não só de seu corpo, mas também de seu discurso, de seu desejo, de sua identidade, de seu direito de ser, até chegar ao seu assassinato. Gisberta foi morta em um processo que durou dias, foi surrada e abusada, seus assassinos se encontravam todas as tardes no prédio abandonado em que Gisberta se fixou, no início levavam comida e conversavam com a travesti, com o tempo outros garotos foram se juntando ao grupo e os encontros eram para espancar Gisberta. No julgamento, descreveram a dinâmica como um ato grupal, como se fosse um jogo coletivo, "ninguém mandava em ninguém”, diziam, e assim foram ceifando o que ainda restava de vida no corpo já estigmatizado socialmente e debilitado pelo HIV.

Na performance de Lobianco vivemos o amor da família, a admiração dos amigos, a crueldade de seus assassinos, a encenação gera todo tipo de emoção. No teatro Dulcina podemos ouvir durante a apresentação as risadas com as piadas que homossexuais ouvem a vida inteira, e também com o deboche clássico presente na comunicação da população LGBTQI ${ }^{3}$ quando usam o dialeto do Pajubát. Conforme a trama vai se desenrolando, o som que se mistura na plateia se confunde, horas de silêncio profundo e ensurdecedor, um choro abafado em narizes que "fungam", respirações descompassadas, tosse, suspiro, a plateia parece acompanhar a dor transmitida pela personagem. Ao fim, ela é aplaudida de pé por muitos minutos, as palmas são fortes, de estampidos que tomam toda a sala, eu diria que são palmas para o ator, o roteirista, os músicos que o acompanham a peça inteira e principalmente para Gisberta, a travesti guerreira que suportou uma vida dura e semanas de tortura.

Podemos perceber que há na performance desses artistas a marca do trânsito, a errância de seus estilos, de suas formas de narrativa, de uma estética que se apresenta nas mais variadas formas, apresentando ao público aquilo que não é hegemônico, denunciando a violência e ao mesmo tempo o amor, a humanidade da existência marginal e errante.

Ao discutir o cenário musical contemporâneo, Guimarães e Braga (2017) ressaltam o aspecto de dissidência do fazer musical LGBTQI.

Entendemos que as produções musicais dissidentes deste tempo provocam exatamente isso: invadem e apropriam-se coletivamente desse lugar do fazer musical, constroem novas experiências porque são outras narrativas: são narrativas da 'bixistranha, ensandecida' ativadas no desvio dos corpos, dos gêneros e das sexualidades, visibilizando outros possíveis. Outros afetos, outros desejos, outros corpos, outros fluxos. (Guimarães \& Braga, 2017, p. 28)

A diversidade de manifestações artísticas que aqui descrevemos - as performances, a ação de Tertuliana (2017) no espaço acadêmico, divulgado para o mundo pelo veículo da internet, Rosa (2016) e a exposição de seu corpo em trânsito em um espaço púbico de Brasília, a cantora Liniker (2017) e sua música, o teatro de Lobianco (2017) e a denúncia 
da violência e intolerância, as tantas poesias, narrativas, biografias, dentre tantas outras formas de arte subversiva - marcam a existência de uma identidade "caleidoscópica", como afirma Luma Nogueira de Andrade (2016, p. 1476). A autora sinaliza em seu trabalho que "Existem travestis de todos os sexos, gêneros e sexualidades" (p. 1488), e essa multiplicidade aparece também na arte, sendo muitas as formas de provocar a visibilidade desses errantes dissidentes.

Apresentamos neste artigo uma discussão, de certo modo errante, que não se pretendia encerrar em si, apresentando algum norteador que classificasse de alguma forma o que seria o transitar corporal, mas sim apresentar algumas das práticas de ruptura com o normativo, com as configurações sociais hegemônicas. $\mathrm{O}$ que se pretendeu aqui foi abrir aquilo que na maior parte do tempo permanece fechado em perspectivas a-históricas, biologizantes e dicotômicas. Nesse sentido, concluímos afirmando nossa ideia de errância corporal como um movimento de caminhar pelo espaço do próprio corpo produzindo, de maneira estética e política, uma construção corporal e singular de si que reflita um percurso existencial que seja poder de expressão e fala, enunciação de modos de existir que escapam da configuração normativa de maneira a anunciar novas possibilidades de ser, de existir, de TRANSexistir.

\section{Notas}

1 Arte Queer é um movimento artístico não oficializado, que ganhou força nos Estados Unidos e na Europa a partir da década de 1980. Suas criações abordam, de forma direta ou indireta, questões relacionadas à homossexualidade, com ligações à arte erótica, à arte conceitual e à arte contextual.

2 Gisberta: Mulher trans, atriz e performer. Gisberta foi agredida e violada sistematicamente por 14 adolescentes durante dias e seu corpo foi encontrado no fundo de um poço; de lá pra cá, Portugal passou a ser "um dos países mais avançados do mundo no tratamento à igualdade de gênero".

3 LGBTQI, sigla que identifica o movimento político de Lésbicas, Gays, Transgêneros, Queer e Intersexo.

4 Pajubá é o nome da linguagem popular constituída da inserção em língua portuguesa de numerosas palavras e expressões provenientes de línguas africanas ocidentais, muito usado pelo chamado povo do Santo, praticantes de religiões afro-brasileiras como candomblé e umbanda, e também por mulheres transsexuais e pela comunidade LGBT. 


\section{Referências}

Alvim, M. B. A. (2014). Poética da experiência: Gestalt-terapia, fenomenologia e arte. Rio de Janeiro: Garamond.

Andrade, L. N. (2016). Travestilidades na carne. In F. Seffner \& M. Caetano (Eds.), Discurso, discursos e contra-discursos latino-americanos sobre a diversidade sexual e de gênero (pp. 1474-1488). Rio Grande/RS: Editora Realize.

Autoria Coletiva. (2017). Antologia Trans: 30 poemas trans, travestis e não-binários. São Paulo: Invisíveis Produções.

Bento, B. A. (2014). Reinvenção do corpo: sexualidade e gênero na experiência transexual. Natal: EDUFR.

Butler, J. (2011). Vida precária. Contemporânea, 1, 13-33.

Butler, J. (2016). Problemas de gênero: feminismo e subversão da identidade. Rio de Janeiro: Civilização Brasileira. (Original publicado em 1990)

Careri, F. (2013). Walkscapes - O caminhar como prática estética. São Paulo: Gili.

Certeau, M. (1994). A invenção do cotidiano: artes do fazer. Petropólis/RJ: Vozes.

Colling, L. (2017). Artivismo das dissidências sexuais e de gênero. Revista Cult, 226(20), 18-34.

Guimarães, R. \& Braga, C. (2017). Vidobras dissidentes na música pop brasileira. Revista Cult, 226(20), 28-31.

Jacques, P. B. (2012). Elogio aos errantes. Salvador: EDUFBA.

Lepecki, J. (2012). Coreopolítica e coreopolícia. Ilha, 13(1), 41-60.

Louro, G. L. (2013). Um corpo estranho: Ensaios sobre a sexualidade e a teoria queer ( $2^{\mathrm{a}}$ ed.). Belo Horizonte: Autêntica.

Lucon, N. (2016). Artista trans, Rosa Luz faz corajosa performance e para rodoviária de Brasília. Recuperado de <http://www.nlucon.com/2016/04/artista-trans-rosa-luz-faz-corajosa.html $>$

Lustosa, T. (2017). Performance Tertuliana no Puta Dei do IMS. Recudperado de < $\underline{\text { https://www. }}$ youtube.com/watch? $\mathrm{v}=\mathrm{qnQiEZPH6ng}>$

Merleau-Ponty, M. (2011). Fenomenologia da Percepção. São Paulo: Martins Fontes. (Original publicado em 1945)

Merleau-Ponty, M. (2012). A prosa do mundo. São Paulo: Cosac Naify. (Original publicado em 1964)

Ortega, F. (2008). O corpo incerto: corporeidade, tecnologias médicas e cultura contemporânea. Rio de Janeiro: Garamond.

Pinto, A. C. (2011). Amanda e Monick. Produção: Departamento de comunicação social, Medonho produções. Direção e roteiro: André da Costa Pinto. Duração: 19’41”. Recuperado de https://www.youtube.com/watch?v=LqzEAai25cE

Russo, J. \& Carrara, S. (2017). Ecos do Puta Dei Precisamos falar sobre isso. IMS - Instituto de Medicina Social, UERJ. Recuperado de <http://site.ims.uerj.br/2017/06/14/ecos-do-puta-deiprecisamos-falar-sobre-isso/>

Silva, H. R. (1993). Travesti: a invenção do feminino. Etnografia. Rio de Janeiro: ISER.

Souza-Ribeiro, R. (2017). Teatro Dulcina. Gisberta. Rio de Janeiro. Recuperado de http://cidadedasartes.rio.rj.gov.br/programacao/interna/922 
FLAVIA FERREIRA SILVA

https://orcid.org/0000-0002-9278-0395

Mestra e doutoranda em Psicologia também pela Universidade Federal do Rio de Janeiro, no PPGP, com bolsa pela Coordenação de Aperfeiçoamento de Pessoal de Nível Superior - CAPES.

Endereço: Rua Almirante Tamandaré, 347, Sala 601, Flamengo, Rio de Janeiro/RJ, CEP $22210-060$.

E-mail: flavia.ferreira@gmail.com

\section{MÔNICA BOTELHO ALVIM}

https://orcid.org/0000-0003-3522-4154

Professora associada do Instituto de Psicologia e do Programa de Pósgraduação em Psicologia da Universidade Federal do Rio de Janeiro, RJ.

E-mail: mbalvim@gmail.com

\begin{tabular}{|l|l|}
\hline Histórico & $\begin{array}{l}\text { Submissão: 11/04/2019 } \\
\text { Aceite: 20/02/2020 }\end{array}$ \\
\hline $\begin{array}{l}\text { Concepção: F.F.S.; M.B.A. } \\
\text { Coleta de dados: NÃO SE APLICA } \\
\text { dos autores }\end{array}$ & $\begin{array}{l}\text { Análise de dados: NÃO SE APLICA } \\
\text { Elaboração do manuscrito: F.F.S. } \\
\text { Crítico revisões de conteúdo intelectual importante: M.B.A. } \\
\text { Aprovação final do manuscrito: F.F.S.; M.B.A. }\end{array}$ \\
\hline $\begin{array}{l}\text { Consentimento } \\
\text { de uso de imagem }\end{array}$ & Não se aplica. \\
\hline $\begin{array}{l}\text { Aprovação, ética } \\
\text { e consentimento }\end{array}$ & Não se aplica. \\
\hline Financiamento & Não se aplica. \\
\hline
\end{tabular}

